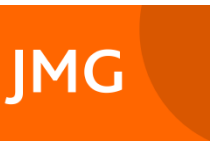

\title{
Phenotypic spectrum associated with de novo and inherited deletions and duplications at 16p11.2 in individuals ascertained for diagnosis of autism spectrum disorder
}

Bridget A Fernandez, Wendy Roberts, Brian Chung, et al.

J Med Genet 2010 47: 195-203 originally published online September 15, 2009

doi: 10.1136/jmg.2009.069369

Updated information and services can be found at:

http://jmg.bmj.com/content/47/3/195.full.html

These include:

References This article cites 29 articles, 7 of which can be accessed free at:

http://jmg.bmj.com/content/47/3/195.full.html\#ref-list-1

Article cited in:

http://jmg.bmj.com/content/47/3/195.full.html\#related-urls

Email alerting

Receive free email alerts when new articles cite this article. Sign up in the service box at the top right corner of the online article.

\section{Notes}

To request permissions go to:

http://group.bmj.com/group/rights-licensing/permissions

To order reprints go to:

http://journals.bmj.com/cgi/reprintform

To subscribe to BMJ go to:

http://journals.bmj.com/cgi/ep 


\title{
Phenotypic spectrum associated with de novo and inherited deletions and duplications at $16 \mathrm{p} 11.2$ in individuals ascertained for diagnosis of autism spectrum disorder
}

\author{
Bridget A Fernandez, ${ }^{1,3}$ Wendy Roberts, ${ }^{5}$ Brian Chung, ${ }^{6}$ Rosanna Weksberg, ${ }_{3}^{6}$ \\ Stephen Meyn, ${ }^{6}$ Peter Szatmari, ${ }^{7}$ Ann M Joseph-George, ${ }^{8,10}$ Sara MacKay, ${ }^{3}$ \\ Kathy Whitten, ${ }^{3}$ Barbara Noble, ${ }^{3}$ Cathy Vardy, ${ }^{2,4}$ Victoria Crosbie, ${ }^{4}$ Sandra Luscombe, \\ Eva Tucker, ${ }^{4}$ Lesley Turner, ${ }^{1,3}$ Christian R Marshall, ${ }^{8}$ Stephen W Scherer ${ }^{8,9}$
}

\begin{abstract}
- Supplementary tables are published online only at http:// jmg.bmj.com/content/vol47/ issue3
\end{abstract}

${ }^{1}$ Discipline of Genetics, Memorial University of Newfoundland, St John's, Newfoundland, Canada ${ }^{2}$ Discipline of Pediatrics Memorial University of Newfoundland, St John's, Newfoundland, Canada ${ }^{3}$ Provincial Medical Genetics Program, Eastern Health, St. John's, Newfoundland Canada ${ }^{4}$ Child Health Program, Eastern Health, St. John's Newfoundland, Canada ${ }^{5}$ The Autism Research Unit, Hospital for Sick Children, Toronto, Ontario, Canada ${ }^{6}$ Department of Pediatrics, Division of Clinical and Metabolic Genetics, Hospital for Sick Children, Toronto, Ontario, Canada ${ }^{7}$ Offord Center for Child Studies,

McMaster University, Hamilton, Ontario, Canada ${ }^{8}$ The Centre for Applied Genomics, Hospital for Sick Children, Toronto, Ontario, Canada ${ }^{9}$ Department of Molecular Genetics, University of Toronto, Toronto, Ontario, Canada ${ }^{10}$ Department of Pediatric Laboratory Medicine, Cytogenetics Laboratory, Hospital for Sick Children, Toronto, Ontario, Canada

\section{Correspondence to}

Bridget Fernandez, Provincial Medical Genetics Program, Health Sciences Center, 300 Prince Philip Drive, St. John's Newfoundland, A1B 3V6, Canada; bfernandez@nl.rogers. com

Received 12 May 2009 Revised 13 August 2009 Accepted 14 August 2009 Published Online First 15 September 2009

\begin{abstract}
Background Recurrent microdeletions and microduplications of $\sim 555 \mathrm{~kb}$ at 16p11.2 confer susceptibility to autism spectrum disorder (ASD) in up to $1 \%$ of ASD patients. No physical or behavioural features have been identified that distinguish these individuals as having a distinct ASD subtype, but clinical data are limited.
\end{abstract}

Methods We report five autistic probands identified by microarray analysis with copy number variation (CNV) of 16 11.2 (three deletions, two duplications). Each patient was assessed for ASD and dysmorphic features. We also describe a deletion positive 26-month-old female who has developmental delay (DD) and autistic features. Results Proband 1 (female with ASD, de novo deletion) is not dysmorphic. Proband 2 (male with autism, de novo deletion) and proband 3 and his brother (males with autism, inherited deletions) are dysmorphic, but the two probands do not resemble one another. The mother of proband 3 has mild mental retardation (MR), minor dysmorphism and meets the criteria for ASD. Proband 4 (dysmorphic autistic male, de novo duplication) had a congenital diaphragmatic hernia. Proband 5 (nondysmorphic ASD female with a duplication) has two apparently healthy duplication positive relatives. Probands 1 and 2 have deletion negative siblings with ASD and Asperger syndrome, respectively. Proband 6 la female with DD and an inherited duplication) is dysmorphic, but has oligohydramnios sequence. Conclusions The phenotypic spectrum associated with CNV at 16p11.2 includes ASD, MR/DD and/or possibly other primary psychiatric disorders. Compared with the microduplications, the reciprocal microdeletions are more likely to be penetrant and to be associated with nonspecific major or minor dysmorphism. There are deletion positive ASD probands with a less severe phenotype than deletion negative ASD siblings underscoring the significant phenotypic heterogeneity.

\section{INTRODUCTION}

Autism (OMIM 209850), typically apparent by the age of 3 years, is characterised by impaired communication, impaired reciprocal social interaction skills, and by restricted repetitive behaviours and interests. Autism spectrum disorder (ASD) is a broader phenotype, which includes autism as well as less severe conditions such as Asperger syndrome and pervasive developmental disorder-not otherwise specified (PDD-NOS). ${ }^{1}$ The prevalence of autism is 3 per 1000 and rises to 6 per 1000 when all forms of ASD are included. ${ }^{2}$ The male to female ratio is $\sim 4: 1$ and after syndromic forms of ASD are excluded, it is associated with an empiric sibling recurrence risk of $5-10 \%{ }^{3}$

The ASDs are aetiologically heterogeneous. About $10 \%$ are associated with a Mendelian syndrome (eg, fragile $\mathrm{X}$ syndrome and tuberous sclerosis complex). Another $5-7 \%$ are associated with a cytogenetically visible chromosome abnormality, the most frequently observed being a maternally derived duplication of $15 q 11-13 .{ }^{4}$ Teratogens, including in utero exposure to rubella and valproate, have also been implicated. 5 The remainder of affected individuals are presumed to have multifactorial forms of ASD and linkage scans have mapped candidate risk loci. ${ }^{6}$ More recently, de novo copy number variations ( $\mathrm{CNVs}$ ) have been observed in $7-10 \%$ of sporadic ASD patients and in $2-3 \%$ of affected individuals from multiplex families. ${ }^{7} 8$

Three studies have recently discovered recurrent microdeletions and microduplications at the 16p11.2 locus in ASD cohorts. $^{8-10}$ This $^{8} 55 \mathrm{~kb}$ CNV region, which is flanked by segmental duplications having $>99 \%$ sequence identity, is presumed to have an elevated mutation rate due to its genomic architecture. ${ }^{11}$ In our previous study, we identified 4/427 ( 1\%) unrelated Canadian ASD patients who had chromosome $16 \mathrm{p} 11.2 \mathrm{CNVs}$. The equivalent change was not observed in 1652 controls. ${ }^{8}$ Weiss and colleagues made a similar observation in 12 of 751 (1.6\%) families having two or more ASD siblings (multiplex families) from the Autism Genetic Resource Exchange (AGRE) repository. ${ }^{10}$ Moreover, they found dosage changes at $16 \mathrm{p} 11.2$ in $5 / 512$ children $(\sim 1 \%)$ who had either developmental delay (DD) or suspected ASD, in 3/299 $(\sim 1 \%)$ patients from an Icelandic ASD cohort, and in $2 / 18834(0.01 \%)$ of Icelandic unscreened controls. Kumar et al found 16p11.2 CNVs in 5/712 $(0.7 \%)$ unrelated autism probands comprised of 410 AGRE cases and 302 probands from the National Institutes of Mental Health Genetics Initiative (total of 87 simplex cases and 635 multiplex cases). ${ }^{9}$ Four of the microdeletion patients reported by Weiss et al overlapped with the Kumar study (see 
Supplementary table 1). Subsequent exon sequencing of eight biological candidate genes within this locus failed to identify any variants associated with ASD. ${ }^{12}$

Bijlsma et $a l^{13}$ have now reported that $14 / 4284$ (0.33\%) individuals referred for mental retardation and/or multiple congenital anomalies carry the same 16p11.2 microdeletion. Only four of the probands were formally assessed for autism, with one receiving a diagnosis. Interestingly, three apparently normal transmitting parents (two mothers, one father) were identified. Here we present detailed genotype-phenotype correlation for six probands with CNV at 16p11.2, emphasising detailed assessment for ASD and dysmorphology in the index case and in the CNV/ ASD positive family members. Coupled with a literature review, our findings reinforce the role of this $16 \mathrm{p} 11.2$ region in ASD, but reveal many complexities in interpreting clinical outcomes.

\section{METHODS}

\section{Human subjects}

ASD cases were collected through a multicentre Canadian research team using common ASD protocols approved by respective research ethics boards of the institutions where clinical evaluations were performed (the Provincial Medical Genetics Program, St John's Newfoundland; the Hospital for Sick Children, Toronto; the Offord Center for Child Studies, Hamilton, Ontario). Informed consent including consent to publish photographs was obtained from each participant or legal guardian. Probands $1-5$ met the criteria for ASD based on Autism Diagnostic Interview-Revised, ${ }^{14}$ Autism Diagnostic Observation Schedule (ADOS) ${ }^{15}$ and clinical history, with the exception of proband 5 who had a Childhood Autism Rating Scale ${ }^{16}$ rather than an ADOS. One of three medical geneticists (BF, RW, SM) reviewed the medical charts and performed physical examinations for dysmorphic features. Additional clinical evaluations included speech assessments (Oral Written and Language Scales, $\mathrm{OWLs}^{17}$ ) and Intelligence Quotient (IO) testing. For the latter, Leiter International Performance scale ${ }^{18}$ was used for those who were young or significantly verbally impaired, and Wechsler Intelligence Scale ${ }^{19}$ was used for those who were able to complete the test.

\section{Microarray analysis}

DNA samples were genotyped using one or more of the Affymetrix 500K, Affymetrix 6.0, or Illumina $1 \mathrm{M}$ single nucleotide polymorphism arrays according to standard protocols (see table 1). ${ }^{8}$ For all microarray platforms, multiple calling algorithms were used to maximise CNV detection (sensitivity) and call accuracy (specificity). For the Affymetrix 500K array, the analysis tools dChip, CNAG, and GEMCA were used while Birdsuite, Partek Genomics Suite, and Affymetrix GTC were used for the analysis of the Affymetrix 6.0 arrays. For Illumina $1 \mathrm{M}$ arrays, the programs Quanti-SNP, PennCNV, and iPattern (unpublished) were employed for $\mathrm{CNV}$ detection. CNVs were merged if they were detected in the same individual by more than one algorithm using the outside probe boundaries. We have observed that those CNVs detected by more than one analysis tool validate at a rate of $>95 \%$ using quantitative polymerase chain reaction (PCR) assays. All 16p11.2 CNVs were detected by all relevant algorithms. We used identical methods to examine 2387 population controls (but not assessed for autism) and found none with CNV of this region ${ }^{820}$; nor was the region identified as variable in the Database of Genomic Variants. ${ }^{21}$

For CNV validation, two independent SYBR Green based quantitative assays were used (primer sequences available upon request) to measure relative copy number in cases and controls between 16p11.2 and a control region (FOXP2). Standard fluorescent in situ hybridisation (FISH) techniques were also used for validation with RP11-114A14 (at 16p11.2) used as a test probe and RP11-553M22 (at 16q22.1) used as a control probe.

\section{RESULTS}

Table 1 and figures 1 and 2 summarise our original findings and table 2 integrates these results with the literature. Our results focus on genotype and phenotype correlations for 16p11.2 CNVs in ASD families. We also examined parents for potential inversions that might predispose to CNV events in children, ${ }^{22}$ but in those tested no inversion was detected (figure $2 \mathrm{~h}, \mathrm{i}$ ).

\section{Proband 1}

This 18-year-old female has ASD and a de novo 16p11.2 microdeletion. While microarray analysis did not identify mosaicism, subsequent FISH testing showed 50\% mosaicism for the deletion (figure $2 \mathrm{e}-\mathrm{g}$ ). Although not examined by a medical geneticist, no dysmorphic features were recorded in her medical chart. At 5 years, her head circumference was $51 \mathrm{~cm}$ (50th centile). Her younger brother was diagnosed with ASD at 10 years, but is microdeletion negative.

\section{Proband 2}

This 13-year-old male has autism and a de novo microdeletion. $\mathrm{He}$ was born to a 26-year-old $\mathrm{G}_{2} \mathrm{P}_{1}$ mother and a 29-year-old father. Pregnancy and delivery at term were uncomplicated. Birth weight was $2665 \mathrm{~g}$ (2nd-9th centile). At 14 months, eye contact deteriorated and he lost a four word vocabulary. By 4 years, he was obese. He was prescribed sertraline for anxiety at 7 years.

At 13 years (figure 3a,b), height was $157 \mathrm{~cm}$ (25th centile), weight was $104.75 \mathrm{~kg}$ (>97th centile), and head circumference was $59 \mathrm{~cm}$ (+3SDs). He had a low nuchal hairline, a short neck and a strikingly flat facial profile with low set ears. Palpebral fissures were narrow and long. Nose was short, with a flat broad nasal root/bridge and a delicate tip. Philtrum was smooth and mouth was downturned. Upper incisors were widely spaced and chin was pointed. Hand length was $17.2 \mathrm{~cm}$ ( $3 \mathrm{rd}-25$ th centile) with distally tapered fingers. Toes were short with $2 / 3$ cutaneous syndactyly (extending half way up the interdigital space). Finger and toenails were thin and deep set. He had micropenis with testicles that were starting to enlarge.

His 15-year-old sister was diagnosed with Asperger syndrome at 12 years, but is microdeletion negative. She is not dysmorphic.

\section{Proband 3}

This 5-year-old male has autism and a microdeletion inherited from his mother who has mild mental retardation (MR) and ASD. He was born to a 29-year-old $\mathrm{G}_{1} \mathrm{P}_{0}$ mother and a 28 -yearold father. Pregnancy was uncomplicated until mother was admitted with an antepartum bleed. He was born at $28^{+3}$ weeks and was extubated within the first $24 \mathrm{~h}$ of life. At 6 weeks, he was discharged from the neonatal intensive care unit (NICU) into foster care. At 14 months, extremities were hypertonic and he was diagnosed with spastic cerebral palsy. He walked at 27 months. At 5 years he had no speech, but had learned a few signs.

At 4.5 years, height was $99.5 \mathrm{~cm}$ (25th centile), weight was $16.5 \mathrm{~kg}$ (50th centile) and head circumference was $51.3 \mathrm{~cm}$ (50th centile). He had a frontal cowlick with a double hair whorl. He had a tall broad forehead with hypertelorism (inner canthal distance $3.4 \mathrm{~cm},>+2 \mathrm{SD}$ ). Midface was hypoplastic and nares were anteverted. Philtrum was smooth and measured $1.2 \mathrm{~cm}$ (3rd-25th centile). His mouth was wide and ears were 


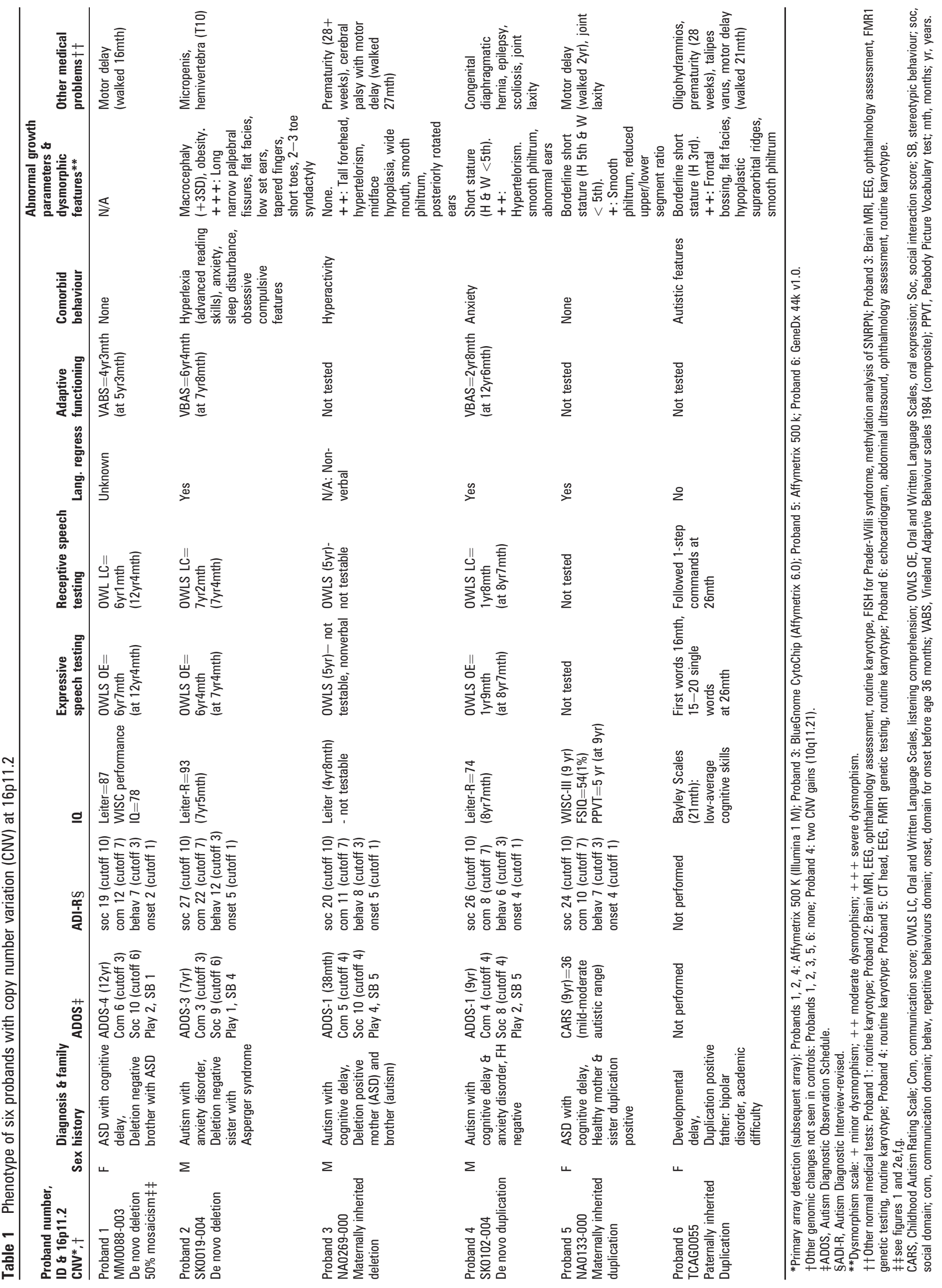


Table 2 Summary of autistic probands with recurrent CNV at 16p11.2, and of the phenotypes and deletion or duplication status of their first degree relatives (this report as well as ${ }^{7-10}{ }^{13}$ )

\begin{tabular}{|c|c|c|c|c|c|}
\hline $\begin{array}{l}\text { ASD } \\
\text { subtype } \\
\text { (proband } \\
\text { or } \\
\text { relatives) }\end{array}$ & $\begin{array}{l}\text { Autistic probands with } \\
16 p 11.2 \text { CNV, } \\
\text { sex of proband } \\
\text { (origin of deletion } \\
\text { or duplication) }\end{array}$ & $\begin{array}{l}\text { Autistic first degree } \\
\text { relatives concordant for } \\
\text { ASD subtype compared } \\
\text { with proband (relative's } \\
\text { deletion or duplication } \\
\text { status, proband's sex) }\end{array}$ & $\begin{array}{l}\text { Autistic first degree } \\
\text { relatives discordant for } \\
\text { ASD subtype compared } \\
\text { with proband (relative's } \\
\text { deletion or duplication } \\
\text { status, proband's sex/ } \\
\text { proband's ASD subtype) }\end{array}$ & $\begin{array}{l}\text { Non-autistic first degree } \\
\text { relatives with deletion } \\
\text { (relative's phenotype, } \\
\text { proband's sex/proband's } \\
\text { ASD subtype) }\end{array}$ & $\begin{array}{l}\text { Non-autistic first degree } \\
\text { relatives with duplication } \\
\text { (relative's phenotype, } \\
\text { proband's sex/proband's } \\
\text { ASD subtype) }\end{array}$ \\
\hline Autism & $\begin{array}{l}\text { Proband 3, } M \text { (mat del) } \\
\text { Proband 2, } M \text { (de novo del) } \\
1 \mathrm{M} \text { (del, gonadal mosaicism) } \\
1 \mathrm{M} \text { (de novo del) } \\
1 \mathrm{M} \text { (de novo del) } \\
1 \mathrm{M} \text { (de novo del) } \\
1 \mathrm{~F} \text { (del, unk) } \\
1 \mathrm{M} \text { (pat del) } \\
\text { Proband 4, } M \text { (de novo dup) } \\
1 \mathrm{M} \text { (mat dup) } \\
1 \mathrm{M} \text { (pat dup) } \\
1 \mathrm{M} \text { (de novo dup) } \\
1 \mathrm{~F} \text { (mat dup) }\end{array}$ & $\begin{array}{l}\text { Proband 3's brother (del-pos, } \\
\text { proband M) } \\
1 \text { sister (del-pos, proband M) } \\
1 \text { brother (del-neg, proband M) } \\
1 \text { brother (del-neg, proband M) } \\
1 \text { brother (del-neg, proband M) } \\
3 \text { brothers (dup-pos, proband M) } \\
1 \text { brother (dup-neg, proband M) }\end{array}$ & None & $\begin{array}{l}1 \text { father (speech delay, } \\
\text { proband } \mathrm{M} / \text { autism) } \\
1 \text { brother (speech disorder } \\
\text { /MR, proband M/autism) }\end{array}$ & $\begin{array}{l}1 \text { sister (normal, proband } \\
\text { M/autism) } \\
1 \text { mother (depression/anxiety/ } \\
\text { learning disability, proband } \\
\text { F/autism) }\end{array}$ \\
\hline ASD & $\begin{array}{l}\text { Proband 1, F (de novo mosaic } \\
\text { del) } \\
1 \mathrm{M} \text { (pat del) } \\
\text { Proband } 5, F \text { (mat dup) }\end{array}$ & $\begin{array}{l}\text { Proband 1's brother (del-neg, } \\
\text { proband F) }\end{array}$ & $\begin{array}{l}\text { Proband 3's mother (del-pos, } \\
\text { proband M/autism) } \\
1 \text { sister (dup-pos, proband } \\
\text { M/autism) }\end{array}$ & $\begin{array}{l}1 \text { father (ADHD, proband } \\
\text { M/ASD) }\end{array}$ & $\begin{array}{l}\text { Proband 5's sister (normal, } \\
\text { female } \\
\text { proband/ASD) } \\
\text { Proband 5's mother (normal, } \\
\text { female } \\
\text { proband/ASD) }\end{array}$ \\
\hline $\begin{array}{l}\text { Asperger } \\
\text { syndrome }\end{array}$ & $\begin{array}{l}\text { 1F (de novo del) } \\
1 \mathrm{~F} \text { (de novo del) }\end{array}$ & None & $\begin{array}{l}\text { Proband 2's sister (del-neg, } \\
\text { proband M/autism) }\end{array}$ & None & None \\
\hline Total & 18 & 10 & 3 & 3 & 4 \\
\hline
\end{tabular}

\footnotetext{
Italicised font, probands and relatives from this report, regular font, previously reported probands and relatives.
}

ADHD, attention deficit hyperactivity disorder; ASD, autism spectrum disorder; MR, mental retardation; M, male; F, female; del, deletion; dup, duplication; pat, paternal; mat, maternal; unk, origin of CNV unknown; del-pos, deletion positive; del-neg, deletion negative; dup-pos, duplication positive; dup-neg, duplication negative.

posteriorly rotated. He had fifth finger clinodactyly and a small umbilical hernia.

His autistic brother also carries the $16 \mathrm{p} 11.2$ microdeletion (see below).

\section{Patient 3b (brother of proband 3)}

This 4-year-old deletion positive boy also has autism. He is the second and only other child of the parents. Mother had threatened labour from 24 weeks and he was born vaginally at 36 weeks. Birth weight was $2800 \mathrm{~g}$ (50th-75th centile), head circumference was $32.5 \mathrm{~cm}$ (50th centile) and birth length was $46.5 \mathrm{~cm}$ (25th-50th centile). He was discharged at 3 days into foster care. At 7 months, he had a urinary tract infection and three febrile seizures. He was treated with phenobarbital until 16 months. He crawled at 18 months and walked at 21 months.

At 3.5 years, height was $105 \mathrm{~cm}$ (90th centile), weight was $16.1 \mathrm{~kg}$ (50th-75th centile) and head circumference was $50.4 \mathrm{~cm}$ (50th centile). He also had a tall broad forehead and resembled his brother. Midface was hypoplastic with a smooth philtrum that measured $0.9 \mathrm{~cm}$ (3rd-25th centile). He had a cupid bow contour of the upper lip, and an everted lower lip. He had low set, posteriorly rotated asymmetric ears and a right helical pit. Distal fingers were broad, fourth toes were curved, and he had a small umbilical hernia.

\section{Patient 3c (mother of proband 3)}

This 35.5-year-old woman was also deletion positive. She required special education and reads at a grade 3 level. She was diagnosed with depression at 12 years with multiple subsequent episodes. At 35, full scale IO (Wechsler Adult Intelligence Scale) ${ }^{19}$ was 56 (0.2 centile). Listening comprehension, OWLs ${ }^{17}$ was at a 13.5 year level. Once her microdeletion was identified, she was assessed for autism, and clinical history and ADOS-4 assessment led to a diagnosis of ASD (communication+social interaction total score $=10$, ASD cutoff=7).
When examined at 35.5 years (figure 3c,d), height was $157 \mathrm{~cm}$ (10th-25th centile), weight was $85.6 \mathrm{~kg}$ (>95th centile) and head circumference was $54.4 \mathrm{~cm}$ (50th centile). She was brachycephalic with a receding hairline. She had deep-set eyes with minor dysmorphism including a smooth philtrum (length $1.5 \mathrm{~cm}, 25 \mathrm{th}-50$ th centile), large ears (length $6.9 \mathrm{~cm},>+2 \mathrm{SD}$ ) and unusually short 5 th toes. She had an unexplained longstanding intention tremor.

\section{Proband 4}

This 15.5-year-old male has autism (simplex case) and a de novo 16 p11.2 microduplication. He had a repaired congenital diaphragmatic hernia $(\mathrm{CDH})$. His other medical problems included epilepsy, an anxiety disorder with good response to fluvoxamine, and scoliosis. He has two other rare CNV gains $(654 \mathrm{~kb}$ and $479 \mathrm{~kb}$ both mapping to $10 \mathrm{q} 11.21$ ) not seen in controls. None of the congenital diaphragmatic hernia loci map to either of these CNVs. When examined at 15.5 years of age, height was $155 \mathrm{~cm}$ $(<5$ th centile), weight was $38.1 \mathrm{~kg}(<5$ th centile) and head circumference was $54.5 \mathrm{~cm}$ (50th centile). He had hypertelorism with a smooth philtrum. Ears were small with curved pinnae. He had long slender fingers and toes. Hand length was $15.8 \mathrm{~cm}$ and foot length was $22.3 \mathrm{~cm}$ (both <3rd centile).

\section{Proband 5}

This 13-year-old girl has ASD and an inherited microduplication, which is also present in her healthy mother and sister. She was born to a 30-year-old $\mathrm{G}_{1} \mathrm{P}_{0}$ mother and a 32-year-old father. Delivery was induced for polyhydramnios at 38 weeks, and there were no neonatal complications. Birth weight was $3505 \mathrm{~g}$ (75th-90th centile), length $52 \mathrm{~cm}$ (90th centile) and head circumference $35.5 \mathrm{~cm}$ (90th centile). When examined at 13 years (figure $3 \mathrm{e}, \mathrm{f}$ ), eye contact was inconsistent. Height was $145.5 \mathrm{~cm}$ (5th centile) with an arm span of $144 \mathrm{~cm}$. Weight was $29.3 \mathrm{~kg}$ 
Figure 1 Pedigrees of families with $16 p 11.2$ copy number variants. Black symbols indicate a diagnosis of autism spectrum disorder (ASD) or autism, the grey symbol indicates Asperger syndrome, the symbol with hatched diagonal lines indicates developmental delay (DD), and the symbol with hatched vertical lines indicates bipolar disorder. Additional clinical details are provided in table 1 . The proband is denoted by an arrow. The deletion in the MM0088 proband was determined to be mosaic (50:50) by fluorescent in situ hybridisation (FISH) analyses.

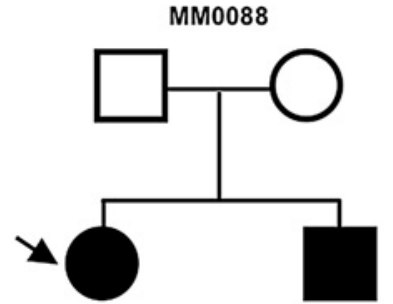

deletion (mosaic)

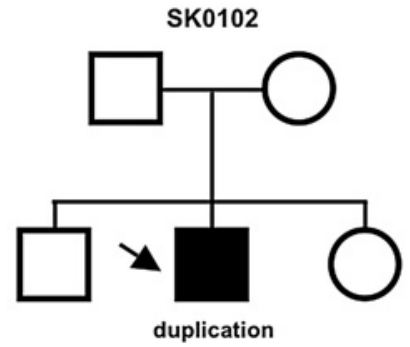

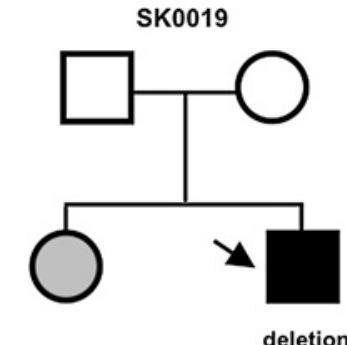

deletion

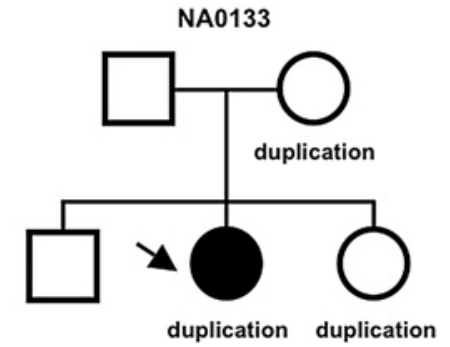

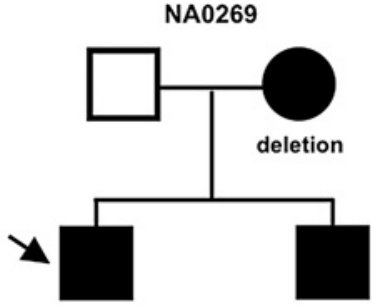

deletion

deletion
$(<5$ th centile) and head circumference was $52 \mathrm{~cm}$ (50th centile). Upper to lower segment ratio was reduced (0.875). She was not dysmorphic, although mild synophrys and a smooth philtrum (a feature seen in her mother) were noted.

Her duplication positive mother is a 44-year-old homemaker with a grade 9 education (figure $3 \mathrm{~g}$ ). Her 8-year-old sister (figure 3f), who also caries the duplication is healthy with no social or academic difficulties (negative Autism Screening Questionnaire ${ }^{23}$ ). Apart from a smooth philtrum in the mother, neither had dysmorphic features.

\section{Proband 6}

This 26-month-old girl has mild developmental delays and a microduplication inherited from her father who left vocational school in grade 11 and who was recently diagnosed with bipolar disorder. The proband was born to a 24 -year-old $\mathrm{G}_{4} \mathrm{P}_{2} \mathrm{~A}_{1}$ mother and a 29-year old father. Pregnancy was complicated by severe oligohydramnios, and maternal smoking and cannabis use. She was delivered vaginally at 38 weeks with a birth weight of $1145 \mathrm{~g}$ (50th-75th centile). Hypotonia and evidence of oligohydramnios sequence (Potters facies, left talipes varus) were noted at birth. She was ventilated for 3 weeks and discharged from hospital at age 78 days. She sat at 14 months, walked at 21 months and first spoke at 16 months. At 21 months, Bayley Infant Scale of Mental Development ${ }^{24}$ showed low-average cognitive skills, borderline-low motor skills and low-average language skills. Her hypotonia improved although she uses orthotics for walking.

When examined at 26 months, eye contact was inconsistent and play was mainly solitary. A formal assessment for autism is pending. Height was $82 \mathrm{~cm}$ (3rd centile), weight was $11.3 \mathrm{~kg}$ (25th centile) and head circumference was $46.5 \mathrm{~cm}$ (10th centile). She had distinctive facial features including frontal bossing with notably receding hairline, hypoplastic supraorbital ridges, sparse eyebrows and eyelashes, deep-set eyes, smooth philtrum, thin upper lip and a flat facial profile (figure $3 \mathrm{~h}$ ). She had single palmar creases and fifth finger clinodactyly (figure $3 \mathrm{i}$ ).

\section{DISCUSSION}

Our collective analyses reveal extensive phenotypic heterogeneity in individuals with ASD and their relatives carrying microdeletion or microduplication of chromosome $16 \mathrm{p} 11.2$. In this case series and in several previous studies reporting indi- viduals with CNV at $16 \mathrm{p} 11.2$, patients were ascertained because of a diagnosis of $\mathrm{ASD}^{79}$ so that autistic individuals may be overrepresented in the literature to date. Nevertheless, a significant trend in the data is that $16 \mathrm{p} 11.2$ microdeletions are more penetrant with respect to ASD and dysmorphic features compared with the reciprocal microduplications.

Excluding probands 1 and 2 from this study (first published by Marshall et al in $2008^{\circ}$ ), 40 microdeletion patients from 27 families have been reported ${ }^{7} 9101325$ (supplementary table 1). The breakdown of diagnoses is as follows: 10 patients had an ASD (table 2), four had DD with autistic features, 17 had DD/ MR without autistic features, three had speech disorders without $M R$, and two had attention deficit hyperactivity disorder (ADHD). One deletion positive female, who was developmentally normal at 3.5 years, had an array because of dysmorphic features and Wilms tumour (proband 25, supplementary table 1). This girl's deletion positive father and two deletion positive mothers of females with MR were normal, but psychometric testing was not performed. ${ }^{13}$ Twenty-four of 27 microdeletion probands had parental testing and the origin was de novo in 16 and inherited in eight.

For 10 previously reported microdeletion patients with $\mathrm{ASD}^{7} 91013$ (supplementary table 1), the lowest reported nonverbal IQ was 73 and two patients had Asperger syndrome. The three deletion patients characterised in this study had ASDs of variable severity (table 1). Probands 1 (ASD) and 2 (autism) are higher functioning while proband 3 and his deletion positive brother (both autism) are non-verbal, compared with a less severe form of ASD in their deletion positive mother. She has mild MR and was only diagnosed with ASD at age 35, after her microdeletion was identified.

Dysmorphology was assessed in 22 of 40 previously reported deletion cases. ${ }^{10} 1325$ The male MZ twins reported by Ghebranious had dysmorphism that was present in a deletion-negative sibling (supplementary table 1 ). ${ }^{25}$ Of the remaining 20 patients, nine were dysmorphic with no common appearance. Our data suggest that the deletion can be associated with variable dysmorphism. Proband 2 has very dysmorphic facial features, digit abnormalities, micropenis and a hemivertebra. Proband 3 and his deletion positive brother share the same dysmorphic facial features, but do not resemble proband 2. The brothers' deletion positive mother has less striking dysmorphism than her sons. 

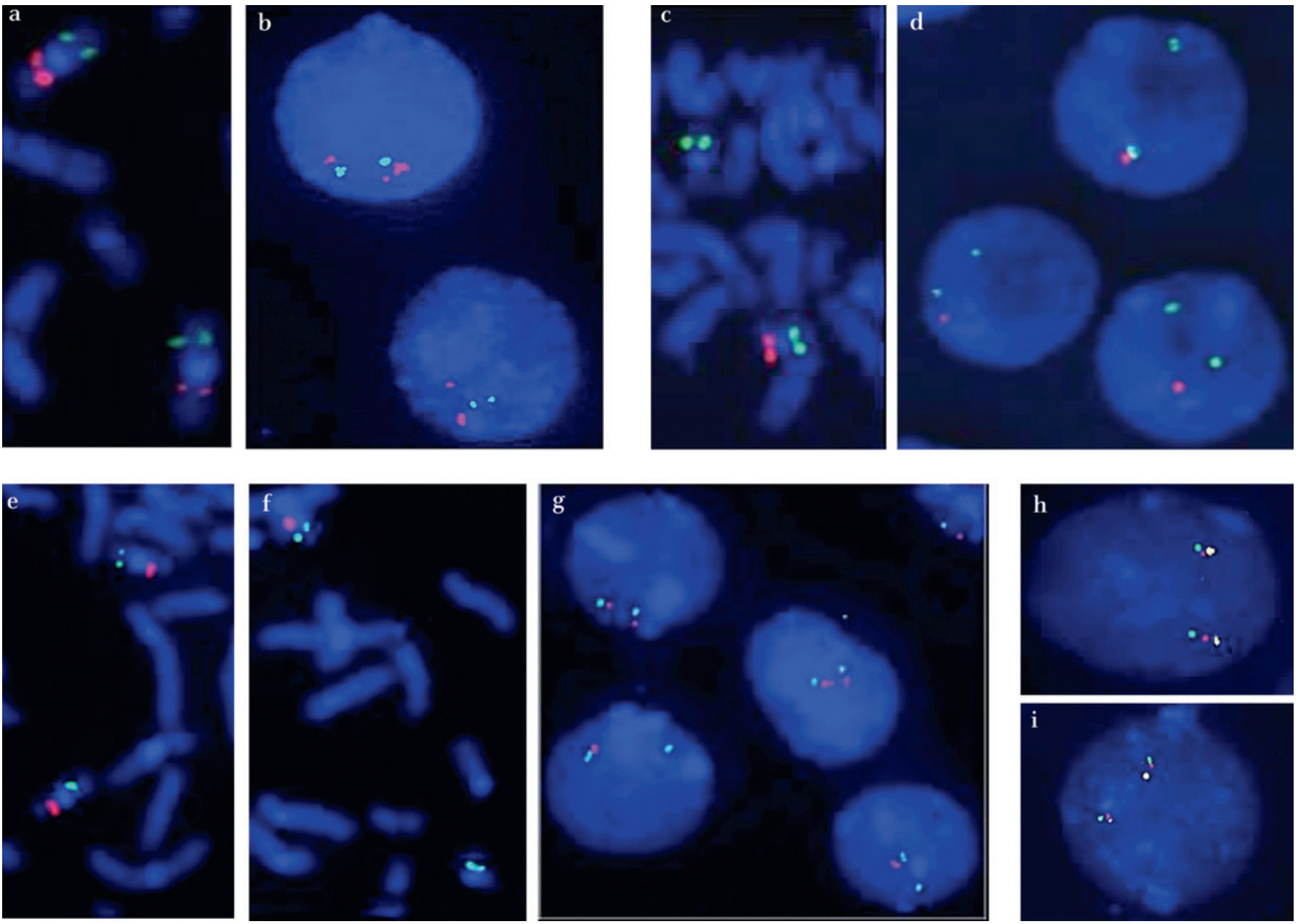

Figure $2(\mathrm{a}-\mathrm{g})$ Fluorescent in situ hybridisation (FISH) testing for 16p11.2 microdeletion or duplication using differentially labelled bacterial artificial chromosome (BAC) clones RP11-114A14 (16p11.2, test probe, Spectrum0range) and RP11-553M22 (16q22.1, control probe, SpectrumGreen). (a and b) Metaphase chromosomes and interphase nuclei from proband 5 (NA0133-000) showing one normal and one enhanced signal. (c and d) Metaphase chromosomes and interphase nuclei from an individual with microdeletion 16p11.2 (AGRE proband AU0938301) showing a single red signal. (e and f) Metaphase chromosomes from proband 1 (MM0088-003) who had a 50\% mosaic microdeletion; 8/15 cells showed a red signal on both homologues (e) and 7/15 cells showed loss of test signal on one homologue (f). $(\mathrm{g})$ Interphase nuclei from proband 1 (MM0088-003) showing a deletion signal pattern in 2/4 cells; 100 nuclei were scored and 48/100 showed a single test probe. (h and i) Inversion testing for SK0102-002 using three colour interphase FISH. $\mathrm{He}$ is the father of proband 4 (SK0102-004 who has a de novo duplication). The three probes are fosmids G248P82830F11 (SpectrumGreen),

G248P87322G6 (Spectrum Orange) and G248P8542C4 (anchor, Biotin detected with Avidin-Cy5). Both cells show a normal probe order. Both parents were examined in eight families (MM0088, SK0102, SK0019 see figure 1; and AGRE families AU0419, AU0298, AU0029, AU0154, AU0938 see

Supplementary table 1). In one exception, the 16p11.2 duplication positive mother from family AU0029 was not tested. Two hundred interphase nuclei were scored for each parent.

We conclude that autistic individuals with microdeletion 16 p11.2 often have a more complex phenotype than those with presumed multifactorial forms of ASD. They are more likely to have additional medical findings including congenital anomalies, dysmorphism, growth disturbance, motor delay and epilepsy. Within ASD research cohorts, there is a need to collect this type of data systematically.

Probands 1 and 2 (deletion positive) both have ASD siblings who are deletion negative (table 1). Four previously reported patients with deletion or duplication negative autistic sibs are summarised in supplementary table 2 (all pairs of brothers). ${ }^{10} 12$ In three of the four sib pairs, the deletion positive male had a less severe phenotype than his deletion negative brother. We add the first two sib pairs who are discordant for the 16p11.2 CNV and gender. Proband 1 (deletion positive female) and her deletion negative brother both have ASD. They have comparable IOs and language abilities, but she is higher functioning, with higher Vineland Adaptive Behavioural
Scale scores. ${ }^{26}$ Proband 2 (deletion positive male) has autism and his deletion negative sister has Asperger syndrome. In both families, the females were less impaired than the males, suggesting that the sex difference that protects females against the development of ASD may also give them a relative advantage even when a rare CNV acts. ${ }^{27}$ These six families demonstrate that even within multiplex families, there is genetic heterogeneity.

Table 2 summarises 18 ASD probands (including five from this report) with CNV at $16 \mathrm{p} 11.2 .^{7-10} 13$ Viewed in this way, the data also support the concept of female gender as protective against ASD. These 18 patients collectively had 10 autistic first degree relatives concordant for ASD subtype (only three were positive for the proband's CNV), and three autistic first degree relatives discordant for ASD subtype. Nine of 10 of the concordant relatives were males (usually of a male proband) and all three discordant relatives were females with a milder ASD than the male proband. 

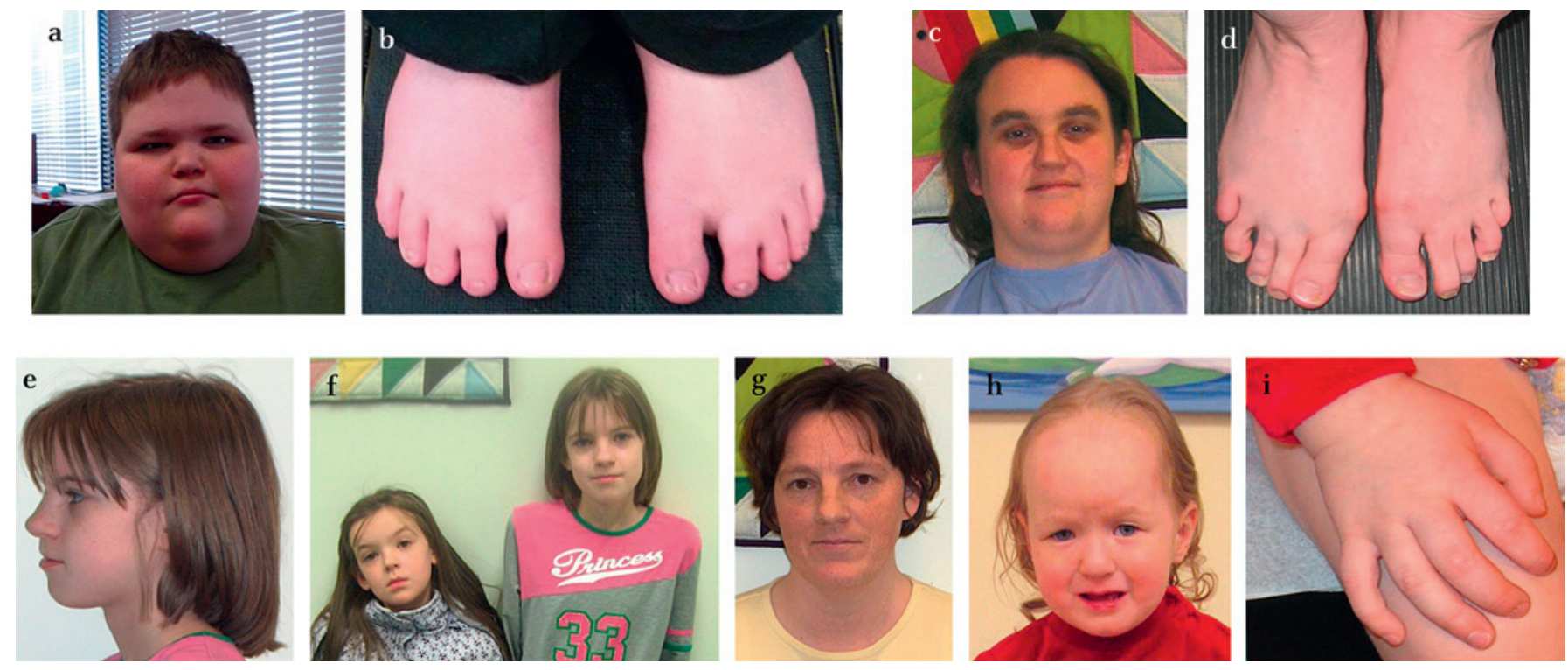

Figure 3 Clinical photographs. (a and b) Proband 2 (de novo deletion 16p11.2). Note long narrow palpebral fissures, short delicate nose, short neck and brachydactyly with 2-3 cutaneous toe syndactyly. (c and d) Mother of proband 3 (both with deletions). Note her large ears, smooth philtrum and short fifth toes. (e) Proband 5 who has a maternally inherited duplication. (f) Proband 5 (note smooth philtrum) and her healthy duplication positive sister. (g) Duplication positive mother of proband 5, who also has a smooth philtrum. (h) Proband 6 (inherited duplication and oliogohydramnios sequence). Note her frontal bossing, receding hairline, hypoplastic supraorbital ridges and smooth philtrum. (i) Proband 6's right hand showing fifth finger clinodactyly. Written consent to publish these images has been obtained from each patient or legal guardian.

Excluding probands 4 and 5 first described by Marshall et al, ${ }^{8}$ 15 microduplication patients have been reported from 10 families ${ }^{9}$ 1028 (supplementary table 3). Eight had ASD (table 2), one had motor delay with autistic features, three had DD without autistic features, two had childhood onset schizophrenia, and one had psychiatric problems. IQs for seven patients ranged from 50-110. Probands 4 (autism) and 5 (ASD) have borderline and mild MR, respectively. Proband 6 is 26 months old and has developmental lags, with abnormal eye contact and play skills. She is relatively young and a formal assessment for autism is pending.

Four of 15 previously reported duplication patients were examined for dysmorphic features and none were identified ${ }^{10}$ (supplementary table 3). Proband 4's dysmorphism and diaphragmatic hernia may be related to the other rare CNVs identified. Proband 6 is also dysmorphic, but at least some of her features are related to in utero compression. Proband 5 and her duplication positive mother and sister were not dysmorphic.

The origin of the duplication was determined for six of 10 previously reported probands. One was de novo and five were inherited (supplementary table 3). Two of the three duplication patients from this report (probands 5 and 6) had inherited duplications. Proband 5's mother and sister are both duplication positive with no overt health problems apart from academic challenges in the mother. This suggests that like microduplications of 22q11.2, 16p11.2 duplications can be associated with a normal phenotype. ${ }^{29}$ Genotype driven studies of general populations $^{30}$ or phenotype driven studies of non-ASD/MR phenotypes might yield more 16p11.2 duplications, with many being inherited because of less selective pressure.

In fact, 16p11.2 dosage changes may confer susceptibility to other psychiatric disorders including ADHD. Of 40 previously reported deletion patients (supplementary table 1), seven had aggression, over activity or $\mathrm{ADHD} .{ }^{9}{ }^{10}$ Of 15 previously reported duplication patients (supplementary table 3), two had childhood onset schizophrenia $^{28}$ (which shares many features with ASD) and one had anxiety and depression. ${ }^{9}$ Weiss et $a l^{10}$ screened other psychiatric cohorts and found the deletion in 1 of 648 patients with schizophrenia, 1 of 420 patients with bipolar disorder, and 1 of 203 patients with ADHD. In our data, probands 2 and 4 had anxiety disorders, proband 3 had hyperactivity, proband 3's deletion positive mother had childhood onset depression, and proband 6's duplication positive father had bipolar disorder.

Our data reconfirm our earlier recommendation ${ }^{8}$ and that of others $^{31}$ to include chromosomal microarray in the assessment of autistic individuals. However, given the complexities of the genotype-phenotype correlations observed, we emphasise the importance of considering as much family information as possible when assessing the impact of the CNV on outcomes. ${ }^{27}$ As one example, by age 3 years, proband 3 was diagnosed with autism and cerebral palsy. If his mother had sought recurrence risk counselling at this stage, a microarray would not have been routinely ordered in our institution. A specific diagnosis would not have been made and the phenotypes of mother and son (minor dysmorphism with $\mathrm{MR}$ and major dysmorphism with autism) may not have been recognised as manifestations of the same genetic disorder. With microarray results now available, proband 3's deletion positive mother has been counselled that each future child is at $50 \%$ risk of inheriting her deletion and that a deletion positive child is at risk for medical problems including, but not limited to, ASD.

As a second example, proband 1 carried a mosaic microdeletion, which likely contributed to her ASD. Nevertheless, her parents then had another more severely affected deletion negative son. We suggest that this couple's future recurrence risk is lower than the $25-35 \%$ empiric risk figure given to parents who have two children with apparently multifactorial ASD, but cannot more precisely quantify this. ${ }^{32} 33$

Glessner et al ${ }^{34}$ recently published a CNV study in which 1995 ASD cases and 2519 controls were screened using the Illumina HumanHap550 Beadchip. The frequency of 16p11.2 CNVs was reported to be similar in the cases and controls (seven deletions in ASD probands vs four in controls; five duplications in ASD probands vs four in controls). The authors screened two ASD cohorts: a discovery cohort of 859 children recruited from multiple US centres, and an AGRE cohort of 1336 cases. The four 
deletions and three duplications identified in the AGRE ASD probands have been reported previously. ${ }^{9} 10$ (supplementary tables 1 and 3). The three unique deletions and the two unique duplications in the discovery cohort are summarised in supplementary table 4.

The controls in this study were reportedly recruited through primary care clinics and ranged in age from 1-19 years. Each child's history was negative for ASD, DD and chronic disease as determined by questionnaires and review of the electronic medical record. It is possible that at least some of the eight control CNVs were identified in young children (<age 2 years) when ASD and the other phenotypes discussed above may not be apparent. As evidenced by proband 3's mother, higher functioning forms of ASD may not be diagnosed until adulthood. Also, the authors did not specify that the control group excluded siblings of the ASD cases. Finally, they reported CNV regions (CNVRs) and several cases and controls appear to have had very small CNVs that are not typical full length deletions or duplications. ${ }^{34}$

We failed to identify any $16 \mathrm{p} 11.2 \mathrm{CNVs}$ in 2387 population controls, perhaps because these individuals were older. Our controls included German adult blood donors and Canadians >age 60 years who were part of a coronary artery disease study. Our negative control results are in keeping with the identification of two deletions in 18834 unscreened Icelandic population controls. ${ }^{10}$

The five deletion positive individuals in our case series all had abnormal phenotypes which we believe are at least partially attributable to the CNV; however, the seven apparently healthy deletion positive individuals reported by Glessner et al and Bijlsma et al ${ }^{13} 34$ suggest that 16 p11.2 deletions (like the duplications) may be incompletely penetrant. Further studies are needed including formal psychometric assessments of apparently healthy individuals with $16 \mathrm{p} 11.2$ microdeletions.

Genetic counselling for parents at risk of having a child with a 16p11.2 CNV is challenging. The phenotypic spectrum includes ASD, MR/DD and/or possibly other primary psychiatric disorders, but a normal outcome is also possible. The latter appears more likely for duplications than for deletions. Deletions can also be associated with non-specific major or minor

\section{Key points}

- We report six probands with copy number variation (CNV) at $16 p 11.2$ (five with an autism spectrum disorder (ASD) and one with developmental delay (DD) and autistic features), emphasising detailed assessment for ASD and dysmorphology in the index case and the CNV/ASD positive family members. Our series includes two ASD probands with microdeletions who each had a deletion negative sibling with ASD, underscoring the genetic heterogeneity that exists even within families.

- We have reviewed previously reported patients $(40$ microdeletion cases from 27 families, 15 microduplication cases from 10 families) and have summarised the information about the behavioural, cognitive and physical phenotypes of individuals with a dosage change at this locus.

- We suggest that the phenotypic spectrum associated with recurrent CNV at $16 \mathrm{p} 11.2$ includes $\mathrm{ASD}$, mental retardation, $\mathrm{DD}$, and/or possibly other primary psychiatric disorders. Compared with the microduplications, the microdeletions are more likely to be penetrant and to be associated with nonspecific major or minor dysmorphism. dysmorphism. Additional case reports as well as prospective cohort analyses of patients with ASD and other disorders will allow these interpretations to be refined.

Acknowledgements We are grateful to the patients and families that participated in this study. We thank Dr. Michael Woods for his critical review and assistance with preparation of this manuscript.

Funding Genome Canada/Ontario Genomics Institute, the Canadian Institutes of Health Research (CIHR), the McLaughlin Centre for Molecular Medicine, the Canadian Institute of Advanced Research, Autism Speaks, the McMaster Children's Hospital Foundation and the Hospital for Sick Children (SickKids) Foundation. CRM is supported by the SickKids Foundation and the National Alliance for Research on Schizophrenia and Depression (NARSAD). SWS holds the GlaxoSmithKline-CIHR Pathfinder Chair in Genetics and Genomics at the University of Toronto and Hospital for Sick Children.

\section{Competing interests None.}

Ethics approval This study was conducted with the approval of the Memorial University of Newfoundland; McMaster University; University of Toronto.

Patient consent Obtained.

Provenance and peer review Not commissioned; externally peer reviewed.

\section{REFERENCES}

1. American Psychiatric Association. Diagnostic and statistical manual of mental disorders. 4th rev ed. Washington: American Psychiatric Association, 1994.

2. Chakrabarti S, Fombonne E. Pervasive developmental disorders in preschool children: confirmation of high prevalence. Am J Psychiatry 2005;162:1133-41.

3. Jones MB, Szatmari P. Stoppage rules and genetic studies of autism. J Autism Dev Disord 1988:18:31-40.

4. Freitag CM. The genetics of autistic disorders and its clinical relevance: a review of the literature. Mol Psychiatry 2007:12:2-22.

5. Arndt TL, Stodgell CJ, Rodier PM. The teratology of autism. Int J Dev Neurosci 2005;23:189-199.

6. Szatmari P, Paterson AD, Zwaigenbaum L, Roberts W, Brian J, Liu XQ, Vincent JB, Skaug JL, Thompson AP, Senman L, Feuk L, Oian C, Bryson SE, Jones MB, Marshall CR, Scherer SW, Vieland VJ, Bartlett C, Mangin LV, Goedken R, Segre A, PericakVance MA, Cuccaro ML, Gilbert JR, Wright HH, Abramson RK, Betancur C, Bourgeron T, Gillberg C, Leboyer M, Buxbaum JD, Davis KL, Hollander E, Silverman JM, Hallmaye J, Lotspeich L, Sutcliffe JS, Haines JL, Folstein SE, Piven J, Wassink TH, Sheffield V, Geschwind DH, Bucan M, Brown WT, Cantor RM, Constantino JN, Gilliam TC, Herbert M, Lajonchere C, Ledbetter DH, Lese-Martin C, Miller J, Nelson S, Samango-Sprouse CA, Spence S, State M, Tanzi RE, Coon H, Dawson G, Devlin B, Estes A, Flodman P, Klei L, McMahon WM, Minshew N, Munson J, Korvatska E, Rodier PM, Schellenberg GD, Smith M, Spence MA, Stodgell C, Tepper PG, Wijsman EM, Yu CE, Roge B, Mantoulan C, Wittemeyer K, Poustka A, Felder B, Klauck SM, Schuster C, Poustka F, Bolte S, Feineis-Matthews S, Herbrecht E, Schmotzer G, Tsiantis J, Papanikolaou K, Maestrini E, Bacchelli $E$, Blasi F, Carone S, Toma C, Van Engeland $H$, de Jonge M, Kemner C, Koop F, Langemeijer M, Hijmans C, Staal WG, Baird G, Bolton PF, Rutte ML, Weisblatt E, Green J, Aldred C, Wilkinson JA, Pickles A, Le Couteur A, Berney T, McConachie H, Bailey AJ, Francis K, Honeyman G, Hutchinson A, Parr JR, Wallace S Monaco AP, Barnby G, Kobayashi K, Lamb JA, Sousa I, Sykes N, Cook EH, Guter SJ Leventhal BL, Salt J, Lord C, Corsello C, Hus V, Weeks DE, Volkmar F, Tauber M, Fombonne E, Shih A, Meyer KJ. Mapping autism risk loci using genetic linkage and chromosomal rearrangements. Nat Genet 2007;39:319-28.

7. Sebat J, Lakshmi B, Malhotra D, Troge J, Lese-Martin C, Walsh T, Yamrom B, Yoon S, Krasnitz A, Kendall J, Leotta A, Pai D, Zhang R, Lee YH, Hicks J, Spence SJ, Lee AT, Puura K, Lehtimaki T, Ledbetter D, Gregersen PK, Bregman J, Sutcliffe JS, Jobanputra V, Chung W, Warburton D, King MC, Skuse D, Geschwind DH, Gilliam TC, Ye K, Wigler M. Strong association of de novo copy number mutations with autism. Science 2007;316:445-9.

8. Marshall CR, Noor A, Vincent JB, Lionel AC, Feuk L, Skaug J, Shago M, Moessner R, Pinto D, Ren Y, Thiruvahindrapduram B, Fiebig A, Schreiber S, Friedman J, Ketelaars CE, Vos YJ, Ficicioglu C, Kirkpatrick S, Nicolson R, Sloman L, Summers A, Gibbons CA, Teebi A, Chitayat D, Weksberg R, Thompson A, Vardy C, Crosbie V, Luscombe S, Baatjes R, Zwaigenbaum L, Roberts W, Fernandez B, Szatmari P, Scherer SW. Structural variation of chromosomes in autism spectrum disorder. Am J Hum Genet 2008;82:477-88.

9. Kumar RA, KaraMohamed S, Sudi J, Conrad DF, Brune C, Badner JA, Gilliam TC, Nowak NJ, Cook EH Jr, Dobyns WB, Christian SL. Recurrent 16p11.2 microdeletions in autism. Hum Mol Genet 2008;17:628-38

10. Weiss LA, Shen Y, Korn JM, Arking DE, Miller DT, Fossdal R, Saemundsen E, Stefansson H, Ferreira MA, Green T, Platt OS, Ruderfer DM, Walsh CA, Altshuler D, Chakravarti A, Tanzi RE, Stefansson K, Santangelo SL, Gusella JF, Sklar P, Wu BL, Daly MJ. Association between microdeletion and microduplication at $16 \mathrm{p} 11.2$ and autism. N Engl J Med 2008;358:667-75.

11. Lupski JR. Genomic rearrangements and sporadic disease. Nat Genet 2007;39: S43-47.

12. Kumar RA, Marshall CR, Badner JA, Babatz TD, Mukamel Z, Aldinger KA, Sudi J, Brune CW, Goh G, Karamohamed S, Sutcliffe JS, Cook EH, Geschwind DH, Dobyns 
WB, Scherer SW, Christian SL. Association and mutation analyses of 16p11.2 autism candidate genes. PLOS ONE 2009;4:e4582.

13. Bijlsma EK, Gijsbers AC, Schuurs-Hoeijmakers JH, van Haeringen A, Fransen van de Putte DE, Anderlid BM, Lundin J, Lapunzina P, Perez Jurado LA, Delle Chiaie B, Loeys B, Menten B, Oostra A, Verhelst H, Amor DJ, Bruno DL, van Essen AJ, Hordijk R, Sikkema-Raddatz B, Verbruggen KT, Jongmans MC, Pfundt R, Reeser HM, Breuning $\mathrm{MH}$, Ruivenkamp CA. Extending the phenotype of recurrent rearrangements of 16p11.2: deletions in mentally retarded patients without autism and in normal individuals. Eur J Med Genet 2009:52:77-87.

14. Lord C, Rutter M, Le Couteur A. Autism diagnostic interview-revised: a revised version of a diagnostic interview for caregivers of individuals with possible pervasive developmental disorders. J Autism Dev Disord 1994;24:659-85.

15. Lord C, Rutter M, Goode S, Heemsbergen J, Jordan H, Mawhood L, Schopler E. Autism diagnostic observation schedule: a standardized observation of communicative and social behavior. J Autism Dev Disord 1989;19:185-212.

16. Schopler E, Reichler RJ, DeVellis RF, Daly K. Toward objective classification of childhood autism: Childhood Autism Rating Scale (CARS). J Autism Dev Disord 1980;10:91-103.

17. Carrow-Woolfolk E. Oral and written language scales: written expression scale manual. Circles Pines: American Guidance Service, 1996.

18. Levine M. Leiter international performance scale: A handbook (Arthur adaptation). Los Angeles: Western Psychological Services, 1986.

19. Weschler D. Manual for the Weschler Intelligence Scale. New York (New York): The Psychological Corporation, 1974.

20. Pinto D, Marshall C, Feuk L, Scherer SW, et al. Copy-number variation in control population cohorts. Hum Mol Genet 2007;16 Spec No. 2:R168-73.

21. lafrate AJ, Feuk L, Rivera MN, Listewnik ML, Donahoe PK, Qi Y, Scherer SW, Lee C. Detection of large-scale variation in the human genome. Nat Genet 2004;36:949-51.

22. Osborne LR, Li M, Pober B, Chitayat D, Bodurtha J, Mandel A, Costa T, Grebe T, Cox S, Tsui LC, Scherer SW. A 1.5 million-base pair inversion polymorphism in families with Williams-Beuren syndrome. Nat Genet 2001;29:321-5.

23. Berument SK, Rutter M, Lord C, Pickles A, Bailey A. Autism screening questionnaire: diagnostic validity. $B r J$ Psychiatry 1999:175:444-51.

24. Kohen-Raz R. Scalogram analysis of some developmental sequences of infant behavior as measured by the Bayley Infant Scale of Mental Development. Genet Psychol Monogr 1967;76:3-21.
25. Ghebranious N, Giampietro PF, Wesbrook FP, Rezkalla SH. A novel microdeletion at 16p11.2 harbors candidate genes for aortic valve development, seizure disorder, and mild mental retardation. Am J Med Genet A 2007;143A:1462-71.

26. Sparrow S, Balla D, Cicchetti DV. Vineland adaptive behavior scales (Survey Forms). Circles Pines: American Guidance Service, 1984.

27. Cook EH Jr, Scherer SW. Copy-number variations associated with neuropsychiatric conditions. Nature 2008;455:919-23.

28. Walsh T, McClellan JM, McCarthy SE, Addington AM, Pierce SB, Cooper GM, Nord AS, Kusenda M, Malhotra D, Bhandari A, Stray SM, Rippey CF, Roccanova P. Makarov V, Lakshmi B, Findling RL, Sikich L, Stromberg T, Merriman B, Gogtay N, Butler P, Eckstrand K, Noory L, Gochman P, Long R, Chen Z, Davis S, Baker C, Eichler EE, Meltzer PS, Nelson SF, Singleton AB, Lee MK, Rapoport JL, King MC, Sebat J. Rare structural variants disrupt multiple genes in neurodevelopmental pathways in schizophrenia. Science 2008;320:539-43.

29. Ou Z, Berg JS, Yonath H, Enciso VB, Miller DT, Picker J, Lenzi T, Keegan CE, Sutton VR, Belmont J, Chinault AC, Lupski JR, Cheung SW, Roeder E, Patel A. Microduplications of 22q11.2 are frequently inherited and are associated with variable phenotypes. Genet Med 2008;10:267-77.

30. Buchanan JA, Scherer SW. Contemplating effects of genomic structural variation. Genet Med 2008:10:639-47.

31. Schaefer GB, Mendelsohn NJ. Clinical genetics evaluation in identifying the etiology of autism spectrum disorders. Genet Med 2008;10:301-305.

32. Ritvo ER, Jorde LB, Mason-Brothers A, Freeman BJ, Pingree C, Jones MB, McMahon WM Petersen PB, Jenson WR, Mo A. The UCLA-University of Utah epidemiologic survey of autism: recurrence risk estimates and genetic counseling. Am J Psychiatry 1989;146:1032-36.

33. Folstein SE, Rosen-Sheidley B. Genetics of autism: complex aetiology for a heterogeneous disorder. Nat Rev Genet 2001;2:943-55.

34. Glessner JT, Wang K, Cai G, Korvatska O, Kim CE, Wood S, Zhang H, Estes A, Brune CW, Bradfield JP, Imielinski M, Frackelton EC, Reichert J, Crawford EL, Munson J, Sleiman PM, Chiavacci R, Annaiah K, Thomas K, Hou C, Glaberson W, Flory J, Otieno F, Garris M, Soorya L, Klei L, Piven J, Meyer KJ, Anagnostou E, Sakurai T, Game RM, Rudd DS, Zurawiecki D, McDougle CJ, Davis LK, Miller J, Posey DJ, Michaels S, Kolevzon A, Silverman JM, Bernier R, Levy SE, Schultz RT, Dawson G, Owley T, McMahon WM, Wassink TH, Sweeney JA, Nurnberger JI, Coon H, Sutcliffe JS, Minshew NJ, Grant SF, Bucan M, Cook EH, Buxbaum JD, Devlin B, Schellenberg GD, Hakonarson $\mathrm{H}$. Autism genome-wide copy number variation reveals ubiquitin and neuronal genes. Nature 2009;459:569-73. 